Delft University of Technology

\title{
An NADH preferring acetoacetyl-CoA reductase is engaged in poly-3-hydroxybutyrate accumulation in Escherichia coli
}

Olavarria, Karel; Carnet, Alexandre; van Renselaar, Joachim; Quakkelaar, Caspar; Cabrera, Ricardo; Guedes da Silva, Leonor; Smids, Aron L.; Villalobos, Pablo Andres; van Loosdrecht, Mark C.M.; Wahl, S. Aljoscha

DOI

10.1016/j.jbiotec.2020.10.022

Publication date

2020

Document Version

Final published version

Published in

Journal of Biotechnology

\section{Citation (APA)}

Olavarria, K., Carnet, A., van Renselaar, J., Quakkelaar, C., Cabrera, R., Guedes da Silva, L., Smids, A. L., Villalobos, P. A., van Loosdrecht, M. C. M., \& Wahl, S. A. (2020). An NADH preferring acetoacetyl-CoA reductase is engaged in poly-3-hydroxybutyrate accumulation in Escherichia coli. Journal of Biotechnology, 325, 207-216. https://doi.org/10.1016/j.jbiotec.2020.10.022

Important note

To cite this publication, please use the final published version (if applicable).

Please check the document version above. 


\title{
An NADH preferring acetoacetyl-CoA reductase is engaged in poly-3-hydroxybutyrate accumulation in Escherichia coli
}

\author{
Karel Olavarria ${ }^{\mathrm{a}, *}$, Alexandre Carnet ${ }^{\mathrm{a}}$, Joachim van Renselaar ${ }^{\mathrm{a}}$, Caspar Quakkelaar ${ }^{\mathrm{a}}$, \\ Ricardo Cabrera $^{\mathrm{b}}$, Leonor Guedes da Silva ${ }^{\mathrm{a}}$, Aron L. Smids ${ }^{\mathrm{a}}$, Pablo Andres Villalobos ${ }^{\mathrm{b}}$, Mark C. \\ M. van Loosdrecht ${ }^{\mathrm{a}}$, S. Aljoscha Wahl ${ }^{\mathrm{a}}$ \\ ${ }^{a}$ Departement Biotechnologie, Faculteit Technische Natuurwetenschappen, Technische Universiteit Delft, Van der Maasweg 9, 2629 HZ, Netherlands \\ ${ }^{\mathrm{b}}$ Departamento de Biología, Facultad de Ciencias, Universidad de Chile, Las Palmeras 3425, Nuñoa, Región Metropolitana, Chile
}

\section{A R T I C L E I N F O}

\section{Keywords:}

acetoacetyl-CoA reductase

NADH

NADPH

oxygen limitation

cofactor specificity

Polyhydroxybutyrate

\begin{abstract}
A B S T R A T
Oxygen supply implies higher production cost and reduction of maximum theoretical yields. Thus, generation of fermentation products is more cost-effective. Aiming to find a key piece for the production of (poly)-3-hydroxybutyrate (PHB) as a fermentation product, here we characterize an acetoacetyl-CoA reductase, isolated from a Candidatus Accumulibacter phosphatis-enriched mixed culture, showing a $\left(k_{\mathrm{cat}}^{\mathrm{NAH}} / \mathrm{K}_{\mathrm{M}}^{\mathrm{NADH}}\right) /\left(k_{\mathrm{cat}}^{\mathrm{NADH}} / \mathrm{K}_{\mathrm{M}}^{\mathrm{NADPH}}\right)>$ 500. Further kinetic analyses indicate that, at physiological concentrations, this enzyme clearly prefers NADH, presenting the strongest NADH preference so far observed among the acetoacetyl-CoA reductases. Structural and kinetic analyses indicate that residues between E37 and P41 have an important role for the observed NADH preference. Moreover, an operon was assembled combining the phaCA genes from Cupriavidus necator and the gene encoding for this NADH-preferring acetoacetyl-CoA reductase. Escherichia coli cells expressing that assembled operon showed continuous accumulation of PHB under oxygen limiting conditions and PHB titer increased when decreasing the specific oxygen consumption rate. Taken together, these results show that it is possible to generate PHB as a fermentation product in E. coli, opening opportunities for further protein/metabolic engineering strategies envisioning a more efficient anaerobic production of PHB.
\end{abstract}

\section{Introduction}

Although (poly)-3-hydroxybutyrate (PHB) was discovered almost 100 years ago (Lemoigne, 1926), studies focused on this polymer have recently burgeoned in response to increasing interest in environment-friendly materials to replace non-biodegradable plastics. However, PHB production cost is still high if compared with fossil-fuel based plastics. One of the factors affecting PHB production cost is the required oxygen supply (Fig. 1). Oxygen supply implies not only extra material and energy input: oxygen itself is also a major electron sink, reducing product yield (Cueto-Rojas et al., 2015).

Carlson and co-workers studied the maximum theoretical PHB yield under anaerobic conditions, given the glycolytic pathways available in Escherichia coli (Carlson et al., 2005). They concluded that co-feeding glucose and acetate with a 2:1 ratio, it is possible to co-generate two 3-hydroxybutyryl monomers and two formate, approaching a carbon yield of 0.8. Remarkably, for their theoretical analysis, Carlson and co-workers assumed an NADH-consuming PHB production pathway. Acknowledging that best studied PHB synthesis pathways include an $\mathrm{NADPH}$-preferring instead of an NADH-preferring acetoacetyl-CoA reductase, they included in their theoretical network a transhydrogenase catalyzing the transference of electrons from NAD(H) pool to NADP $(\mathrm{H})$ pool. They acknowledged that the activity of this transhydrogenase will consume energy, decreasing the yield. However, if reduction of acetoacetyl-CoA to R-3-hydroxybutyryl-CoA is driven by $\mathrm{NADH}$, the activity of the energy consuming transhydrogenase is not necessary, and it would be possible to produce PHB as a fermentation product.

On the other hand, while different genes encoding for the enzymes required for the conversion of acetyl-CoA to PHB have been identified in

\footnotetext{
* Corresponding author.

E-mail addresses: kogamez@gmail.com (K. Olavarria), carnetalexandre@gmail.com (A. Carnet), joachimvrens@gmail.com (J. van Renselaar), casparquakkelaar@

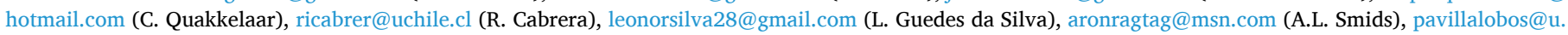
uchile.cl (P.A. Villalobos), M.C.M.vanLoosdrecht@tudelft.nl (M.C.M. van Loosdrecht), S.A.Wahl@tudelft.nl (S.A. Wahl).
} 
many organisms, the successful expression in $E$. coli of the phaCAB operon from Cupriavidus necator (Schubert et al., 1988) opened the way to tens of research projects focused on engineering the PHB accumulation. Given the cofactor preference of the acetoacetyl-CoA reductase from $C$. necator $\left(\mathrm{AAR}^{\mathrm{Cn}}\right.$ ), the reduction of acetoacetyl-CoA to R-3-hydroxybutyryl-CoA using such enzyme is coupled to NADPH consumption. An NADPH-consuming PHB production pathway implies competition for NADPH between PHB and biomass formations. Under these circumstances, the best growers are also the worst producers, leading to instability in the production strain. To avoid this problem, nitrogen-poor media are frequently employed to hinder biomass formation. Nonetheless, this approach affects protein and nucleotide synthesis, compromising the bio-conversion global rate (Chen et al., 2019).

Previous publications reported the use of NADH-preferring acetoacetyl-CoA reductases from Allochromatium vinosum and Halomonas bluephagenesis for PHB accumulation (de Las Heras et al., 2016; Ling et al., 2018). However, in those studies the cofactor preference was evaluated through a comparison between activities obtained at a single substrate and a single cofactor concentration. Moreover, product inhibition by $\mathrm{NAD}^{+}$and $\mathrm{NADP}^{+}$were not evaluated, and saturation constants were not reported. Considering that, in vivo, NADPH/NADP ${ }^{+}$and $\mathrm{NADH} / \mathrm{NAD}^{+}$ratios are different (Andersen and von Meyenburg, 1977) and that these ratios change depending on physiological conditions (de Graef et al., 1999; Krapp et al., 2011), the assessment of the cofactor preference of any acetoacetyl-CoA reductase should be evaluated at physiologically meaningful NADPH/NADP ${ }^{+}$and $\mathrm{NADH} / \mathrm{NAD}^{+}$ratios. Therefore, the information provided in those previous reports is not enough to ensure the use of NADH over NADPH under physiological conditions.

Looking for an NADH-preferring acetoacetyl-CoA reductase engaged in PHB accumulation, we decided to study the enzyme from the bacterium Candidatus Accumulibacter phosphatis $\left(\mathrm{AAR}^{\mathrm{CAp}}\right)$. The choice of this organism was based on the following observations. First, this organism is able to anaerobically convert acetate and glucose equivalents into PHB with full electron conservation (Fig. 1C). Therefore, it naturally does what Carlson and co-workers found as the ideal scenario for anaerobic PHB accumulation. Second, genomic and transcriptomic data indicate that this organism lacks the enzymes catalyzing the reactions of the oxidative branch of pentose-phosphate pathway (Garcia Martin et al., 2006), a common source of NADPH. Furthermore, no gene encoding for an $\mathrm{NADP}^{+}$-depending non-phosphorylating glyceraldehyde-3-phosphate dehydrogenase was found in this bacterium. Therefore, oxidation of glucose equivalents should yield NADH. Third, if $\mathrm{AAR}^{\mathrm{CAp}}$ is an NADPH-preferring enzyme, electrons derived from glucose equivalents oxidation (carried as NADH) must be transferred to NADPH by some transhydrogenase mechanism. Given the redox potential of $\mathrm{NAD}(\mathrm{H})$ and $\mathrm{NADP}(\mathrm{H})$ pools, transfer of reducing equivalents from the former to the latter pool requires energy (Reich and Sel'kov, 1981; Spaans et al., 2015). A more parsimonious and energetically cheaper solution is to have an NADH-preferring acetoacetyl-CoA reductase.

In the genome-scale metabolic network of $\mathrm{Ca}$. A. phosphatis derived from meta-genomics data, $\mathrm{AAR}^{\mathrm{CAp}}$ was annotated as an NADPHpreferring enzyme (Oyserman et al., 2016). Nevertheless, to the best of our knowledge, the kinetic properties of $\mathrm{AAR}^{\mathrm{CAp}}$ have not yet been characterized. The direct use of NADH to drive the reduction of acetoacetyl-CoA to R-3-hydroxybutyryl-CoA has basic and applied

A

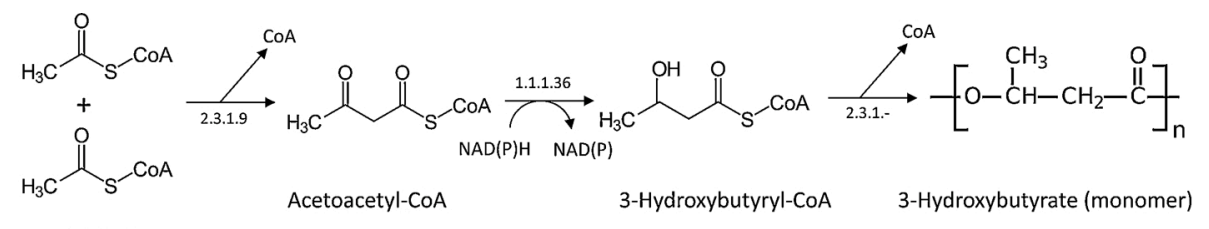

Acetyl-CoA
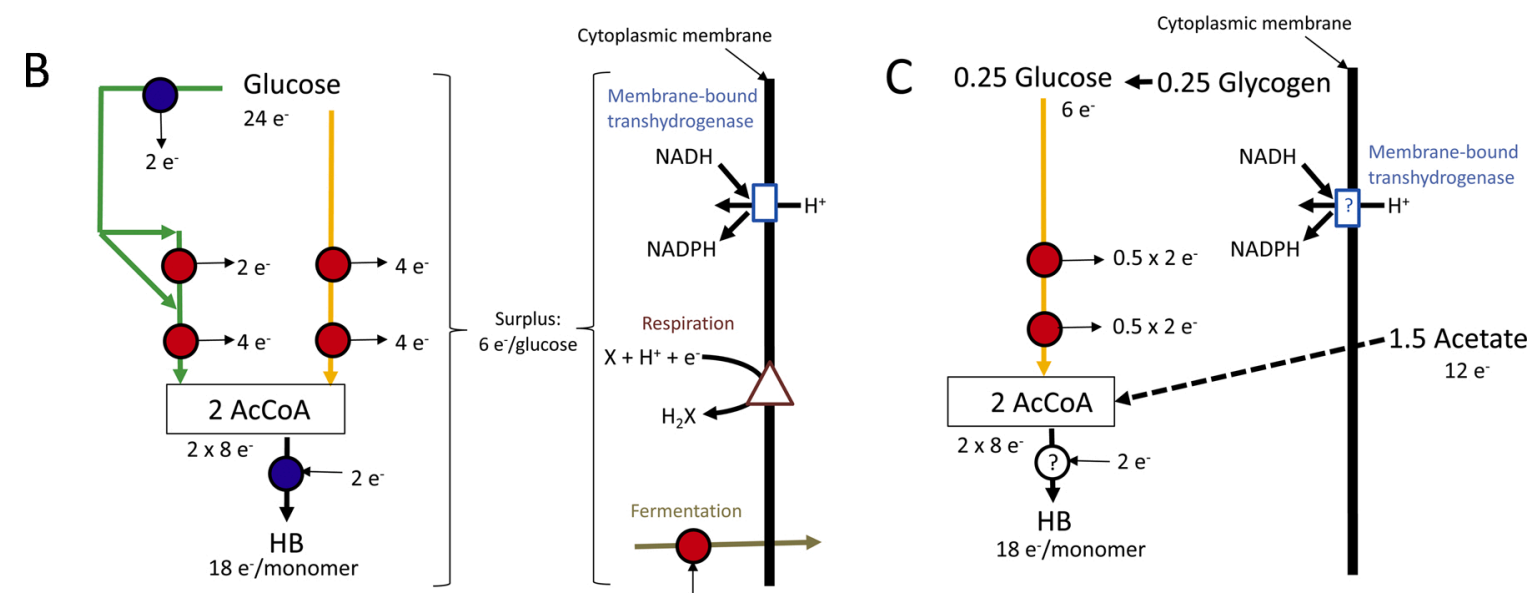

Fig. 1. Electron transfer from carbon source(s) to PHB. NAD(H)-driven processes are represented by red circles and NADP(H)-driven processes by blue circles. A: PHB formation pathway. The enzymes catalyzing the steps involved in this conversion are identified using their Enzyme Commission (E.C.) codes. B: In the most studied cases-such as recombinant E. coli expressing phaCAB genes from C. necator-glucose is catabolized by Embden-Meyerhof (in orange) or Entner-Doudoroff pathway (in green), yielding two acetyl-CoA (AcCoA) per glucose and eight electrons carried by $\mathrm{NADP}^{+}$and/or NAD ${ }^{+}$. One monomer of hydroxybutyrate (HB) contains 18 electrons, and could be form from two acetyl-CoA (16 electrons) and two electrons carried by NADPH. Therefore, there is a surplus of six electrons per glucose that must flow to other electron acceptors (an external acceptor in the case of Respiration, an internally generated acceptor in the case of Fermentation). If glucose oxidation happens only through Embden-Meyerhof pathway, then participation of an energy-dissipating membrane-bound transhydrogenase is also required to transfer electrons from NADH to NADPH. C: In the case of $\mathrm{Ca}$. Accumulibacter phosphatis, PHB formation takes place under anaerobic conditions. Acetyl-CoA is coming from an internal glycogen reserve and from external acetate, with full electron conservation. Acetate must be taken up and activated to become acetyl-CoA (several steps, represented with a dashed line). The genes encoding for the enzymes catalyzing the reactions of the oxidative branch of pentoses-phosphate pathway or Entner-Doudoroff pathway have not been found in this organism. If PHB accumulation is driven by NADPH, some transhydrogenase mechanism would be required. However, transhydrogenase activity has not been definitively confirmed. If PHB accumulation is driven by NADH, then NADH generated in the lower Embden-Meyerhof pathway could be used to drive PHB formation. 
implications. From the basic science perspective, it would mean that $\mathrm{Ca}$. A. phosphatis developed a mechanism to transfer electrons from glycolysis to PHB accumulation without involving an energy-consuming transhydrogenase. From the applied science perspective, it would mean that PHB can be produced as a fermentation product, avoiding competition for NADPH between biomass and PHB accumulation.

Aiming to find a bona fide NADH-preferring acetoacetyl-CoA reductase suitable for PHB accumulation, we characterized here the cofactor preference of an acetoacetyl-CoA reductase obtained from a Ca. A. phosphatis-enriched mixed culture. Moreover, we investigated the role of some key residues in the cofactor discrimination and we observed engagement of this enzyme in PHB accumulation.

\section{Material and Methods}

\subsection{DNA manipulations and strain construction}

All the steps for the construction of the several plasmids and strains employed in this research are detailed in Supplementary Material 1. Relevant information about the strains, primers and plasmids employed in this research are in the Supplementary Table 1, Supplementary Table 2 and Supplementary Table 3. DNA sequence maps of all the constructed plasmids can be found in the open access repository "NADH-driven polyhydroxybutyrate accumulation in E. coli dataset 2" available at Mendeley data. The access link is: https://doi.org/10.17632/ 954dxdncrv.1

\subsection{Cell-free extracts preparation}

Cells from $\mathrm{Ca}$. A. phosphatis were obtained from a $\mathrm{Ca}$. A. phosphatisenriched mixed culture. This $\mathrm{Ca}$. A. phosphatis-enriched culture was prepared as described by Smolders and co-workers (Smolders et al., 1994). In the case of $E$. coli, for all the here-studied strains, cells from previously isolated colonies were inoculated in Lysogenic Broth and aerobically grown for 16 hours at $37^{\circ} \mathrm{C}$, in an orbital shaker at $180 \mathrm{rpm}$. Ampicillin $(100 \mu \mathrm{g} / \mathrm{mL})$ or Kanamycin $(30 \mu \mathrm{g} / \mathrm{mL})$ was added, when required, to select cells carrying plasmids. Cultures had an optical density at $600 \mathrm{~nm}$ between 2.0 and 3.0 when cells were collected.

Broth samples (approx. $10 \mathrm{~mL}$ ) were collected from $E$. coli cultures and the bioreactor containing cells of $\mathrm{Ca}$. A. phosphatis. These samples were centrifuged $\left(2500 \mathrm{x} \mathrm{g}, 10 \mathrm{~min}, 4^{\circ} \mathrm{C}\right)$ and extracellular media were discarded. Pellets were re-suspended in $10 \mathrm{~mL}$ of Buffer A $(50 \mathrm{mM}$ Tris $(\mathrm{pH}$ 8), $5 \mathrm{mM} \mathrm{MgCl}_{2}, 5 \mathrm{mM} \mathrm{NaCl}$ ). Cellular suspensions were centrifuged again $\left(2500 \mathrm{x} \mathrm{g}, 10 \mathrm{~min}, 4^{\circ} \mathrm{C}\right)$ and supernatants were discarded. After this second centrifugation step, pellets were re-suspended in $10 \mathrm{~mL}$ of Buffer A supplemented with $2 \mathrm{mM}$ (L + D) 1,4-dithiothreitol (DTT) and cOmplete $^{\mathrm{TM}}$ protease inhibitor cocktail (Roche), following manufacturer's instructions. Cells were disrupted by sonication in an Ultrasonics ${ }^{\mathrm{TM}} \mathrm{S}$ 250A Analog Ultrasonic Cell Disruptor (Branson), with output power set at level three, $30 \%$ duty cycle, for 3 minutes per sample. Cellular suspensions were kept on ice while being sonicated to avoid overheating and protein denaturation. The resulting cellular suspensions were centrifuged (15000x g, $45 \mathrm{~min}, 4^{\circ} \mathrm{C}$ ). The obtained cell-free extracts were used for enzymatic assays. The protein concentration in the cell-free extracts was determined using the Bradford protein assay reagent (Bio-Rad) and bovine serum albumin (Bio-Rad) as standard (Bradford, 1976).

\subsection{Enzyme purification and characterization}

For over-expression of poly-histidine-tagged forms of the proteins encoded by phaB ${ }^{\mathrm{CAp} 6}$, phaB ${ }^{\mathrm{Cnecator}}$ and phaB ${ }^{\text {Chimera }}$, the plasmids pCOLAHis-phaB ${ }^{\text {CAp6 }}$, pCOLA-His-phaB ${ }^{\text {Cnecator }}$ and pCOLA-His-phaB ${ }^{\text {Chimera }}$ were introduced in BL21(DE3) cells. Protein purification was achieved following a method previously described (Olavarria et al., 2015). Purity of the protein preparations (over $95 \%$ ) was assessed by SDS-PAGE.

The substrates employed for enzymatic assays were purchased from
Sigma ((L + D) 3-hydroxybutyryl-CoA, $\mathrm{NAD}^{+}, \mathrm{NADP}^{+}, \mathrm{NADH}$ and NADPH) and Santa Cruz Biotechnology (acetoacetyl-CoA) and all had analytical grade quality. NADH and NADPH were freshly prepared by dissolving them in Buffer A. Acetoacetyl-CoA, $\mathrm{NAD}^{+}$and $\mathrm{NADP}^{+}$were freshly dissolved in des-ionized water (resistivity $18.2 \mathrm{M} \Omega^{*} \mathrm{~cm}$ at $25^{\circ} \mathrm{C}$ ). Substrate concentration in these stock solutions was estimated by spectrophotometry, dissolving samples taken from the stocks in $50 \mathrm{mM}$ MOPS (pH 7), $5 \mathrm{mM} \mathrm{MgCl}_{2}, 5 \mathrm{mM} \mathrm{NaCl}$. The reactions were monitored in Buffer A at $30^{\circ} \mathrm{C}$. All the kinetic assays were performed in a Synergy HTX plate reader (Biotek), using path length correction. While some reactions were monitored at $310 \mathrm{~nm}$ to detect small changes in acetylCoA concentration, others were monitored at $360 \mathrm{~nm}$ to avoid absorbance values above 2.0 leading to the optical artefact known as "stray light" (Cavalieri and Sable, 1974). To calculate acetoacetyl-CoA reductase activity, it was considered that, during the reactions, both acetoacetyl-CoA and $\mathrm{NAD}(\mathrm{P}) \mathrm{H}$ are consumed with a stoichiometric ratio $1: 1$. The apparent molar extinction coefficients were $\varepsilon^{\text {AcAcCoA, }}$ $310=11000 \quad \mathrm{M}^{-1} \mathrm{~cm}^{-1}$ (Stern, 1956), $\varepsilon^{\mathrm{NAD}(\mathrm{P}) \mathrm{H}, 310}=3340 \quad \mathrm{M}^{-1} \mathrm{~cm}^{-1}$, $\varepsilon^{\mathrm{AcAcCoA}, 360}=900 \mathrm{M}^{-1} \mathrm{~cm}^{-1}$ (Stern, 1956), and $\varepsilon^{\mathrm{NAD}(\mathrm{P}) \mathrm{H}, 360}=4275$ $\mathrm{M}^{-1} \mathrm{~cm}^{-1}$. The enzyme concentration in working stocks was determined using the Bradford protein assay reagent (Bio-Rad) and bovine serum albumin (Bio-Rad) as standard (Bradford, 1976).

Some kinetic parameters were assessed through analyses of reaction progress curves while other were obtained studying the initial rates at different substrate concentrations. To estimate initial rates, pseudolinear temporal changes in absorbance were considered within time frames during which less than $5 \%$ of the initial substrate had been consumed. Enzyme stability was evaluated with the test described by Selwyn (1965). Global fitting of reaction progress curves to different mechanisms was evaluated by a model discrimination algorithm included in the software DYNAFIT (Biokin, version 4.08.137) (Kuzmic, 1996). Raw kinetic data and DYNAFIT scripts are in the open access repository "NADH-driven polyhydroxybutyrate accumulation in $E$. coli dataset 2" available at Mendeley data.

\subsection{Protein structure analysis}

For homology modeling of $\mathrm{AAR}^{\mathrm{CAp}}$, the X-ray crystal structure of a putative acetoacetyl-CoA reductase from Burkholderia cenocepacia bound to $\mathrm{NADP}^{+}$(PDB ID: 4K6F) was used as template. In the asymmetric unit, $\mathrm{NADP}^{+}$ligand was present at two active sites of the tetramer. In order to model the presence of $\mathrm{NAD}^{+}$in the $\mathrm{AAR}^{\mathrm{CAp}}$ active site, we deleted the atomic coordinates of the 2'-phosphate group of $\mathrm{NADP}^{+}$in $4 \mathrm{~K} 6 \mathrm{~F}$. Modeling was performed using Modeller (Sali and Blundell, 1993) with $\mathrm{NAD}^{+}$as fixed ligand. Fifty models were created and ranked according to the Discrete Optimized Protein Energy (DOPE) score. The final model was subjected to energy minimization using the YASARA web server (Krieger et al., 2009). The software VMD (Humphrey et al., 1996) was used to visualize structures and Multiseq analysis environment (Roberts et al., 2006) was used for structural superposition.

\subsection{Continuous culture}

Setup and operation of the continuous culture was as previously described (Olavarria et al., 2019). Dilution rate was fixed to $0.1 \mathrm{~h}^{-1}$. Cellular PHB content was measured by Isotope dilution mass spectrometry (IDMS), using the method described by Velasco Alvarez and co-workers (Velasco Alvarez et al., 2017). Details about medium composition; control of temperature, $\mathrm{pH}$, dissolved oxygen; quantification of biomass concentration; quantification of organic compounds and PHB quantification can be found in Supplementary Material 4. Biomass composition $\quad\left(\mathrm{C}_{1} \mathrm{H}_{1.6749} \mathrm{~N}_{0.255} \mathrm{O}_{0.3453} \mathrm{~S}_{0.0069} \mathrm{P}_{0.0063} ; \quad \mathrm{M}_{\mathrm{wx}}=23.184\right.$ $\mathrm{gCDW} / \mathrm{CmolX}$; Reduction degree $=4.292$ ) considered plasmid and heterologous protein burden. The unbalanced experimentally assessed rates, together with their associated errors, were the input to calculate reconciled rates, consistent with the mass and electron conservation laws. 


\section{Results and Discussion}

\subsection{Cells from a Ca. A. phosphatis-enriched mixed culture showed a high} NADH-dependent acetoacetyl-CoA reductase activity

Use of NADH or NADPH for the reduction of acetoacetyl-CoA was observed first in a cell-free extract from a $\mathrm{Ca}$. A. phosphatis-enriched mixed culture. Cell-free extracts obtained from E. coli K-12 MG1655 cultures, with or without the plasmid pBBRMCS-2-phaCAB ${ }^{\text {Cnecator }}$, were employedascontrols.GiventhekineticparametersoftheAAR ${ }^{\mathrm{Cn}}\left(\mathrm{K}_{\mathrm{M}}^{\mathrm{A}-}\right.$ cAcCoA(NADPH) $=9 \mu \mathrm{M}, \mathrm{K}_{\mathrm{M}}^{\mathrm{NADPH}}=19 \mu \mathrm{M}(28)$ ), the conditions of the assay (acetoacetyl-CoA $200 \mu \mathrm{M}$, NADPH $200 \mu \mathrm{M}$ ) should be saturating for this enzyme.

As expected, the cell-free extract from $E$. coli cells expressing the phaCAB genes from $C$. necator showed a higher acetoacetyl-CoA reductase activity with NADPH than with NADH (Table 1). However, in the cell-free extract from the $\mathrm{Ca}$. A. phosphatis-enriched mixed culture, activity using NADH was 60 times higher than activity with NADPH. Moreover, this NADH-depending activity was four times higher than the NADPH-dependent activity observed in the cell-free extract from $E$. coli cells carrying several episomal copies of the phaCAB genes from $C$. necator per cell. These results suggested that (i) acetoacetyl-CoA reductase is expressed at high levels in $\mathrm{Ca}$. A. phosphatis and (ii) AARCAp should prefers NADH instead of NADPH. However, we considered that to endorse the claiming of NADH preference, it was necessary to explore the kinetic behavior of the purified enzyme in a wider range of substrate and cofactor concentrations, and explore the strength of product inhibition.

\subsection{The cloned phaB gene encodes for an NADH-preferring acetoacetyl- $\mathrm{Co} A$ reductase}

Using primers targeting the amino acid encoding sequence of the gene named CAP2UW1_3919 in KEGG database (GenBank: ACV37169.1) and metagenomic DNA obtained from the Ca. A. phosphatis-enriched mixed culture, three slightly different nucleotide sequences were obtained from four sequenced clones (Supplementary Material 1, Supplementary Fig. 1). Most of the differences in DNA sequences did not result in changes in the encoded amino acids. None of these sequences matched $100 \%$ with the reference sequence CAP2UW1_3919. Therefore, it is possible that the cloned genes do not correspond to the same species whose genome was previously assembled and annotated. It had been impossible to isolate colonies of $\mathrm{Ca}$. A. phosphatis so far, and it is likely that different closely related species are grouped under this taxonomic name. However, amino acid identity was over $93 \%$ in all the sequenced clones. Moreover, the residues D94, K99, Y185, Q147 and Q150, identified as key residues for the enzymatic activity in $\mathrm{AAR}^{\mathrm{Cn}}$ (Kim et al., 2014), were conserved in the cloned sequences. Therefore, we considered those cloned genes as phaB homologues. Because the biological meaning of the observed DNA and protein polymorphism is not clear, for further characterization we chose the clone with the highest identity respect to the reference sequence: phaB ${ }^{\mathrm{CAp}} 6$ (89 \% DNA identity, $95 \%$ amino acid identity). A group of amino acids relevant for cofactor specificity (see Section 3.3) in

\section{Table 1}

Specific AAR activities, using NADH or NADPH, in cell-free extracts from $E$. coli expressing the phaCAB genes from $\mathrm{C}$. necator and from a $\mathrm{Ca}$. A. phosphatisenriched mixed culture

\begin{tabular}{|c|c|c|}
\hline Biological sample & cofactor & mean $\pm \mathrm{SD}(\mathrm{U} / \mathrm{mg})$ \\
\hline E. coli MG1655 + pBBRMCS-2-phaCAB ${ }^{\text {Cnecator }}$ & NADH & $0.026 \pm 0.001$ \\
\hline E. coli MG1655 + pBBRMCS-2-phaCAB ${ }^{\text {Cnecator }}$ & NADPH & $0.196 \pm 0.021$ \\
\hline Ca. A. phosphatis-enriched mixed culture & NADH & $0.720 \pm 0.094$ \\
\hline Ca. A. phosphatis-enriched mixed culture & NADPH & $0.011 \pm 0.002$ \\
\hline
\end{tabular}

${ }^{1} \mathrm{U} / \mathrm{mg}=1 \mu \mathrm{mol}^{*} \mathrm{~min}^{-1}$ per milligram of cytoplasmic proteins.
phaB ${ }^{\mathrm{CAp}} 6$ was identical to the reference protein sequence.

Initial rates using purified enzyme showed that the protein encoded by phaB ${ }^{\mathrm{CAp}} 6$ was able to catalyze the reduction of acetoacetyl-CoA, using both NADH and NADPH, but with very different rates $\left(14 \pm 2 \mu \mathrm{mol}^{*} \mathrm{~min}^{-1 *} \mathrm{mg}^{-1}\right.$ and $0.07 \pm 0.02 \mu \mathrm{mol}^{*} \mathrm{~min}^{-1 *} \mathrm{mg}^{-1}$ respectively, acetoacetyl-CoA $100 \mu \mathrm{M}, \mathrm{NAD}(\mathrm{P}) \mathrm{H} 100 \mu \mathrm{M})$. On the other hand, the enzyme was also able to catalyze the oxidation of $(L+D)-3-$ hydroxybutyryl-CoA $(100 \mu \mathrm{M})$ using $\mathrm{NAD}^{+}(1 \mathrm{mM})$ as cofactor $\left(0.61 \pm 0.01 \mu \mathrm{mol}^{*} \mathrm{~min}^{-1 *} \mathrm{mg}^{-1}\right)$. However, no oxidation of $(\mathrm{L}+\mathrm{D})-3$ hydroxybutyryl-CoA was detected when using $\operatorname{NADP}^{+}(1 \mathrm{mM})$ as cofactor. Because $(\mathrm{L}+\mathrm{D})$-3-hydroxybutyryl-CoA is a mix of two isomers, these results did not enable to discriminate the stereo-isomery of the product(s) generated during acetoacetyl-CoA reduction. Nevertheless, they are consistent with the NADH- and NADPH-linked activities registered in the cell-free extract from the $\mathrm{Ca}$. A. phosphatis-enriched culture. Therefore, given the high DNA and amino acid identities, and the observed enzymatic activities, we considered the purified enzyme an acetoacetyl-CoA reductase from $\mathrm{Ca}$. A. phosphatis (AAR ${ }^{\mathrm{CAp}}$ ).

Analyses of progress curves from reactions with different initial concentrations of NADH or NADPH, and initial concentration of acetoacetyl-CoA $(400 \mu \mathrm{M})$ fixed, were performed to estimate some kinetic parameters. The same approach was employed to study cases where initial acetoacetyl-CoA concentration was varying and initial NADPH concentration was fixed $(300 \mu \mathrm{M})$. Nevertheless, when acetoacetyl-CoA concentration varied while keeping fixed initial NADH concentration, we observed non-regular oscillations in the absorbance. Keeping in mind that substrate inhibition at different concentrations of NADH has been reported for other homologues (Haywood et al., 1988; Fukui et al., 1987; Ploux et al., 1988; Mothes and Babel, 1994), we tested different initial concentrations of NADH, but we did not find a way to prevent these oscillations. Therefore, in this specific case, kinetic parameters were obtained fitting the initial rates versus acetoacetyl-CoA concentration data to the simple Michaelis-Menten model, keeping initial NADH concentration fixed at $300 \mu \mathrm{M}$. In the conditions chosen for the enzymatic assays, partial enzyme inactivation was observed when enzyme concentration was below $1 \mathrm{nM}$. Therefore, enzyme inactivation was considered when fitting progress curves data.

A compilation of the obtained kinetic parameters is presented in Table 2. The physical meaning of $K_{M}$ parameters depends on the model employed to fit the related experimental data. The estimates of $K_{\mathrm{M}}^{\mathrm{AcAcCoA}}$ and $k_{c a t}^{\text {AcAcCoA }}$ using NADH were obtained using the rapid-equilibrium model. The other kinetic parameters were obtained using the steadystate (Briggs-Haldane) approach. As expected, the turnover constants $\left(k_{\text {cat }}\right)$ for each cofactor were very similar, either when obtained varying the concentrations of substrate or cofactor (Table 2).

The individual analysis of the kinetic parameters enabled a first-sight comparison of the performances of AAR ${ }^{\mathrm{CAP}}$ using NADH or NADPH. Using $\mathrm{NADH}, K_{\mathrm{M}}$ of both substrate and cofactor were lower, $k_{\text {cat }}$ was higher, and $\mathrm{NAD}^{+}$inhibited the rates less than $\mathrm{NADP}^{+}$. Cofactor preference is often expressed as the ratio between the catalytic efficiencies $\left(k_{c a t} / K_{\mathrm{M}}\right)$ estimated for each cofactor. A comparison between the acetoaacetyl-CoA reductases that had been kinetically characterized showed that $\mathrm{AAR}^{\mathrm{CAp}}$ has the lowest $k_{\text {cat }} / K_{\mathrm{M}}$ for NADPH and the second highest $k_{\text {cat }} / K_{\mathrm{M}}$ for $\mathrm{NADH}$, only after the homologue from Halomonas boliviensis (see

Table 2

Kinetic parameters observed for the purified $\mathrm{AAR}^{\mathrm{CAp}}$. The best fitted values are accompanied by the $95 \%$ confidence intervals (in parentheses). AcetoacetylCoA was abbreviated as AcAcCoA.

\begin{tabular}{lll}
\hline & $\mathrm{NAD}(\mathrm{H})$ & $\mathrm{NADP}(\mathrm{H})$ \\
\hline$K_{M}(\mu \mathrm{M})$ & $7.7(6.74,8.67)$ & $44.3(40.4,48.5)$ \\
$k_{c a t}\left(\mathrm{~s}^{-1}\right)$ & $8.9(8.8,9.0)$ & $0.09(0.092,0.098)$ \\
$K_{i c}^{\mathrm{NAD}(\mathrm{P})}(\mu \mathrm{M})$ & $54.5(44.8,66.0)$ & $1.27(1.19,1.35)$ \\
$K_{M}^{\mathrm{AcAcCoA}}(\mu \mathrm{M})$ & $56.7(42.7,74.5)$ & $318(303,334)$ \\
$k_{\text {cat }}^{\text {AcAcCoA }}\left(\mathrm{s}^{-1}\right)$ & $11.6(10.5,12.9)$ & $0.131(0.127,0.136)$ \\
\hline
\end{tabular}


Supplementary Table 4). However, the $k_{\text {cat }} / K_{\mathrm{M}}$ for NADPH of the acetoacetyl-CoA reductase from $H$. boliviensis is almost three times higher than its $k_{\text {cat }} / K_{\mathrm{M}}$ for NADH. Therefore, according to such criterion, the acetoacetyl-CoA reductase from $H$. boliviensis is not a NADH-preferring enzyme.

Anyways, it is important to highlight that, for multi-substrates reactions, the comparison between the $k_{\text {cat }} / K_{\mathrm{M}}$ obtained with different substrates or cofactors reflects better the preference when the concentration of the co-substrate is saturating, a situation not necessarily occurring under physiological conditions. In our specific case, the low $K_{i c}^{\mathrm{NAD}(\mathrm{P})}$ values indicate that in vivo $\mathrm{AAR}^{\mathrm{CAp}}$ activity should be highly dependent on $\mathrm{NAD}(\mathrm{P})$ concentration and, therefore, on NAD(P)H/NAD (P) ratios. Because these ratios depend on the physiological conditions, cofactor preference is a dynamic property rather than a static number. For the calculation of this dynamic preference, we implemented a quantitative approach considering the variation of $\mathrm{NAD}^{+}, \mathrm{NADP}^{+}, \mathrm{NADH}$, and NADPH concentrations inside physiologically feasible ranges.

For our quantitative approach, we applied the generic BiBi rate equation proposed by Rohwer and co-workers (Rohwer et al., 2006). Using this generic equation, the rate of NADH consumption in the reaction catalyzed by $\mathrm{AAR}^{\mathrm{CAp}}$ can be written as:

$$
v^{N A D H}=\frac{k_{\text {cat }}^{N A D H *} E^{*} \frac{N A D H^{*} A C A C C O A}{K^{N A D H *} K^{A C A C C O A}} *\left(1-\frac{N A D^{*} 3 H B C O A}{N A D H^{*} A C A C C O A^{*} K_{e q}}\right)}{\left(1+\frac{N A D H}{K^{N A D H}}+\frac{3 H B C O A}{K^{3 H B C O A}}\right) *\left(1+\frac{A C A C C O A}{K^{A C A C C O A A}}+\frac{N A D}{K^{N A D}}\right)}
$$

where $K^{N A D H}, K^{A c A c C O A}, K^{3 H B C o A}$ and $K^{N A D}$ are dissociation constants associated to the interactions between the corresponding ligands and different forms of the enzyme. However, in vivo, $\mathrm{NAD}^{+}$and $\mathrm{NADH}$ binding will be affected by $\mathrm{NADP}^{+}$and NADPH concentrations because they can also bind to the enzyme. Considering NADPH and $\mathrm{NADP}^{+}$as competitive inhibitors of NADH and $\mathrm{NAD}^{+}$binding, the terms $K^{\mathrm{NADH}}$ and $K^{N A D}$ were multiplied by the factor $\left(1+\mathrm{NADPH} / \mathrm{K}^{\mathrm{NADPH}}+\mathrm{NADP} /\right.$ $\mathrm{K}^{\mathrm{NADP}}$ ). After introducing such modifications, the equation was written $k_{\text {cat }}^{\text {reverse }}=\frac{0.61 * k_{\text {cat }}^{\text {forward }}}{14}$

The value $K_{e q}=92$ was obtained from literature (Ritchie et al., 1971). Although this latter value was estimated for reactions using $\mathrm{NADPH}$, according to calculations using Equilibrator (Flamholz et al., 2012), $K_{e q}$ does not vary significantly after substituting NADP(H) by $\mathrm{NAD}(\mathrm{H})$. This way, $K_{N A D H}^{3 H B C O A}=32 \mu \mathrm{M}$ was calculated. This value is very similar to $K_{M}^{3 H B C O A}=33 \mu \mathrm{M}$ estimated by Haywood and co-workers while studying the acetoacetyl-CoA reductase from C. necator (Haywood et al., 1988). Making a similar assumption for the reaction using NADP(H), $K_{N A D P H}^{3 H B C O A}=44300 \mu \mathrm{M}$ was calculated.

However, beyond the availability of the required kinetic parameters, to obtain a physiologically meaningful result, it is important to evaluate the rate expressions with physiologically feasible substrate, product and cofactors concentrations. Because their ability of binding to other biomolecules, free $\mathrm{NAD}(\mathrm{P})(\mathrm{H})$ concentrations are difficult to measure, and many experimentally reported values represent thermodynamically unfeasible states, as demonstrated by Canelas and co-workers (Canelas, 2008). To overcome these problems, we calculated cofactor concentration ranges consistent with the thermodynamic constraints enabling the operation of glycolysis (Kummel et al., 2006; Henry et al., 2007). In the case of $\mathrm{NADH} / \mathrm{NAD}^{+}$ratios, it is know that these values depend on the redox potential of the available electron acceptor (de Graef et al., 1999). This way, we explored $\mathrm{NADH} / \mathrm{NAD}^{+}$ratios in the range between 0.03 (fully aerobic) and 0.71 (no external electron acceptor), according to experimentally determined values (de Graef et al., 1999). Regarding the $\mathrm{NADPH} / \mathrm{NADP}^{+}$ratios, there is a wide range of reported values in literature, from 0.32 (Chassagnole et al., 2002) to 60 (Bennett et al., 2009). Total moieties sizes of $\left(\mathrm{NAD}^{+}+\mathrm{NADH}\right)=1470+100=1570 \mu \mathrm{M}$ and $\left(\mathrm{NADP}^{+}+\mathrm{NADPH}\right)=195+62=257 \mu \mathrm{M}$ were considered, according to the data from Chassagnole and co-workers (Chassagnole et al., 2002). Therefore, to calculate the ranges of individual cofactors concentrations, the following systems of simple algebraic equations were solved: as:

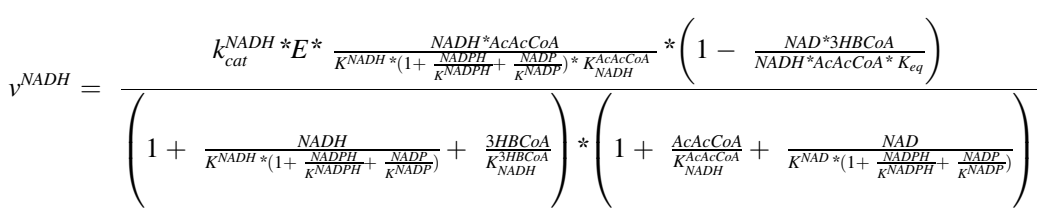

Clearly, it was possible to write a homologue equation describing the rate of NADPH consumption. Considering the experimentally determined $K_{\mathrm{M}}$ and $K_{i c}$ as good approximations of the dissociation constants of the generic equation, the parameters $k_{c a t}^{N A D H}, k_{c a t}^{N A D P H}, K^{N A D H}, K^{N A D P H}$, $K_{N A D H}^{A C A C C O A} K_{N A D P H}^{A C A C C A}, K^{N A D}$ and $K^{N A D P}$ were immediately available. The parameter $K_{N A D H}^{3 A B C O A}$ was not experimentally determined but it was estimated taking advantage of the Haldane relationship:

$K_{N A D H}^{3 H B C O A}=\frac{K_{e q}{ }^{*} k_{c a t}^{\text {reverse } *} K^{N A D H *}{ }^{\text {AcAcCOA }}}{k_{\text {cat }}^{\text {forward } *} K^{N A D}}$

where $k_{\text {cat }}^{\text {reverse }}$ was calculated from the relationship between the $V^{\max }$ of the forward $\left(14 \pm 2 \mu \mathrm{mol}^{*} \mathrm{~min}^{-1 *} \mathrm{mg}^{-1}\right)$ and the backward $\left(0.61 \pm 0.01 \mu \mathrm{mol}^{*} \mathrm{~min}^{-1 *} \mathrm{mg}^{-1}\right)$ reactions, measured with purified enzyme:

\begin{tabular}{|c|c|c|}
\hline & $\mathrm{NAD}(\mathrm{H})$ & NADP(H) \\
\hline $\begin{array}{l}\text { More oxidized } \\
\text { moiety }\end{array}$ & $\begin{array}{l}\frac{N A D H}{N A D}=0.03(\mathrm{I}) \\
N A D+N A D H=1570 \text { (II) } \\
\text { Solutions: } \\
\text { NAD }=1524 \mu \mathrm{M} \\
\text { NADH }=46 \mu \mathrm{M}\end{array}$ & $\begin{array}{l}\frac{N A D P H}{N A D P}=0.32(\mathrm{I}) \\
N A D P+N A D P H=257(\mathrm{II}) \\
\text { Solutions: } \\
\mathrm{NADP}=195 \mu \mathrm{M} \\
\mathrm{NADPH}=62 \mu \mathrm{M}\end{array}$ \\
\hline $\begin{array}{l}\text { More reduced } \\
\text { moiety }\end{array}$ & $\begin{array}{l}\frac{N A D H}{N A D}=0.71(\mathrm{I}) \\
N A D+\mathrm{NADH}=1570 \text { (II) } \\
\text { Solutions: } \\
\mathrm{NAD}=918 \mu \mathrm{M} \\
\mathrm{NADH}=652 \mu \mathrm{M}\end{array}$ & $\begin{array}{l}\frac{N A D P H}{N A D P}=60(\mathrm{I}) \\
N A D P+N A D P H=257 \text { (II) } \\
\text { Solutions: } \\
\text { NADP }=4 \mu \mathrm{M} ; \mathrm{NADPH}=253 \\
\mu \mathrm{M}\end{array}$ \\
\hline
\end{tabular}

Regarding acetoacetyl-CoA concentration, the equilibrium constant of the reaction catalyzed by the thiolase (E.C. 2.3.1.9), $K_{e q}=1.1 \pm 0.2$ * $10^{-5}$ (Lan and Liao, 2012) indicates that cytoplasmic acetoacetyl-CoA concentrations must be very low for the operation of this reaction in the forward direction. For example, considering acetyl-CoA and 
coenzyme A concentrations reported by Bennett and co-workers (Bennett et al., 2009) (610 and $1400 \mu \mathrm{M}$ respectively), acetoacetyl-CoA concentration must be $0.03 \mu \mathrm{M}$ or lower. However, such a low concentration would represent a kinetic problem for the reaction catalyzed by $\mathrm{AAR}^{\mathrm{CAp}}$. The existence of substrate channeling between the enzymes thiolase and acetoacetyl-CoA reductase could be a solution for this problem. Indeed, evidence of substrate channeling between these enzymes had been recently found (Tippmann et al., 2017; Vögeli et al., 2018). To overcome this uncertainty, for our calculations we assumed an acetoacetyl-CoA concentration of $22 \mu \mathrm{M}$, as reported by Bennett and co-workers.

At the same time, the term (1-((NAD * 3HBCoA)/(NADH * AcAcCoA $\left.* \mathrm{~K}_{\mathrm{eq}}\right)$ )) in the rate equation describing NADH consumption must be higher than 1, otherwise the reaction occurs in the backward direction. Using this term, it is possible to calculate the maximal R-3-hydroxybutyryl-CoA concentration, corresponding to a situation of thermodynamic equilibrium:

$3 H B C o A^{\max }=\frac{N A D H^{*} A c A c C o A^{*} K_{e q}}{N A D}$

In the more extreme case (fully aerobic conditions, NADH/ $\mathrm{NAD}^{+}=0.03$ ), using the experimentally validated value of $K_{e q}=92$ and an acetoacetyl-CoA concentration of $22 \mu \mathrm{M}$ :

$3 H B C o A^{\max }=0.03 * 22 \mu \mathrm{M} * 92=61 \mu \mathrm{M}$

Given all these kinetic parameters, substrate, product and cofactors concentrations, it was possible to calculate the ratio $\mathrm{R}=v^{N A D H} / v^{N A D P H}$, which indicates the relative use of NADH over NADPH by the enzyme $\mathrm{AAR}^{\mathrm{CAp}}$. According to this approach, $\mathrm{AAR}^{\mathrm{CAp}}$ will have an $\mathrm{R}$ between 4 and 3975. It is important to notice that the relative use is independent of the enzyme concentration, as the terms $E$ in the numerator and denominator of $\mathrm{R}=v^{N A D H} / v^{N A D P H}$ cancel each other.

As a way to validate this novel approach, we applied it to calculate the $\mathrm{R}=v^{N A D H} / v^{N A D P H}$ for the enzyme $\mathrm{AAR}^{\mathrm{Cn}}$, a well-documented NADPH-preferring homologue (Haywood et al., 1988; Matsumoto et al., 2013). As expected, the resulting analysis showed that $\mathrm{AAR}^{\mathrm{Cn}}$ has a preference for NADPH over NADH between 17 and 33136. The relative use of NADH over NADPH (or vice versa) by $\mathrm{AAR}^{\mathrm{CAp}}$ and $\mathrm{AAR}^{\mathrm{Cn}}$ at physiological NADPH/NADP ${ }^{+}$and $\mathrm{NADH} / \mathrm{NAD}^{+}$ratios is presented in Fig. 2.

It was not possible to calculate the relative use of NADH and NADPH by the acetoacetyl-CoA reductases from $H$. bluephagenesis and A. vinosum, either comparing the $k_{\text {cat }} / K_{\mathrm{M}}$ for NADH and NADPH or using the above described approach because the required kinetic parameters are not available. In the case of $H$. bluephagenesis, the values $k_{c a t}^{N A D H}=72$ $\mathrm{s}^{-1}$ and $k_{c a t}^{N A D P H}=31 \mathrm{~s}^{-1}$ can be calculated from the reported maximum velocities and the molecular weight of the monomer (Ling et al., 2018). However, no saturation constants were reported.

Summarizing, our kinetic analyses show that (i) at physiological concentrations, $\mathrm{AAR}^{\mathrm{CAp}}$ will largely prefer NADH over NADPH and (ii) $\mathrm{AAR}^{\mathrm{CAp}}$ is the acetoacetyl-CoA reductase with the highest preference for NADH among the homologues that have been kinetically characterized so far.

\subsection{The residues between E37 and P41 have an important role in the observed cofactor specificity}

Previous studies tried to identify which are the structural determinants of the cofactor preference observed in some acetoacetyl-CoA reductases. De las Heras and co-workers suggested (i) the absence of the $\mathrm{R} 40$ residue present in the NADPH-preferring $\mathrm{AAR}^{\mathrm{Cn}}$ and (ii) the presence of the acidic E37 residue as the key determinants of the use of NADH by the acetoacetyl-CoA reductase from A. vinosum (de Las Heras et al., 2016). On the other hand, Chen and co-workers pointed to (i) the substitution of the G35, S38 and R40 (according to residue numeration in $\mathrm{AAR}^{\mathrm{Cn}}$ ) by other residues and (ii) the presence of the acidic $\mathrm{E} 40$ residue (aligned with the $\mathrm{E} 37$ of the acetoacetyl-CoA reductase from A. vinosum) as the key determinants for the use of NADH by the acetoacetyl-CoA reductase from $H$. bluephagenesis (Ling et al., 2018). However, these hypotheses were not experimentally tested. AAR ${ }^{\text {CAP }}$ also has the E37 residue but comparing the NADH- and the NADPH-linked acetoacetyl-CoA reductase specific activities recorded in cell-free extracts, the ratio $720 / 11 \approx 65$ observed in the $C a$. A. phosphatis-enriched culture is a value higher than the ratio $56 / 5 \approx 24$ observed in H. bluephagenesis (Ling et al., 2018) or the ratio 185/39 $\approx 5$ observed in the yeasts expressing the acetoacetyl-CoA reductase from $A$. vinosum (de Las Heras et al., 2016). Therefore, we reasoned that other structural determinants should have a role in the cofactor discrimination in AAR $^{\text {CAp }}$.

Looking for a deeper understanding of the interactions determining the high selectivity toward NADH observed in AAR ${ }^{\mathrm{CAp}}$, we carried out a homology modeling, using the structure from Burkholderia cenocepacea as template. The choice of this species to guide the generation of the homology model is supported by the fact of $B$. cenocepacea being the closest species where a tridimensional structure of an acetoacetyl-CoA reductase complexed with a cofactor is available (Supplementary Material 2). Since both the K40 residue observed in $A A R^{\mathrm{CAp}}$ and the R40 residue in $\mathrm{AAR}^{\mathrm{Cn}}$ have a positively charged side-chain, making a simple

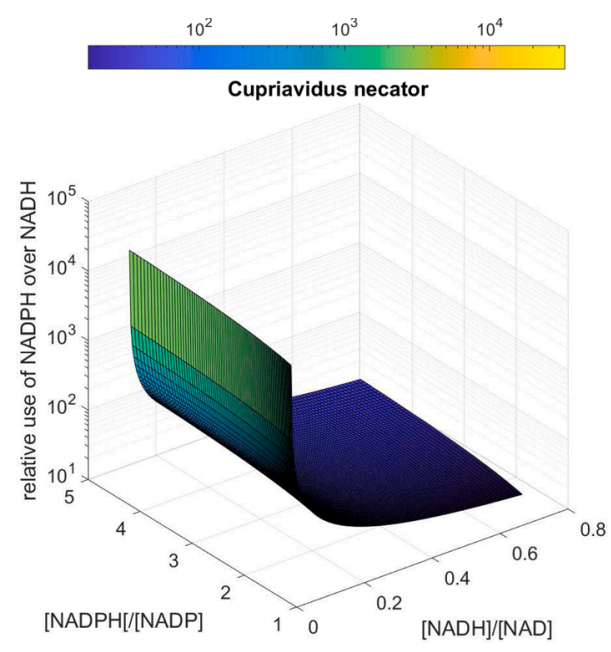

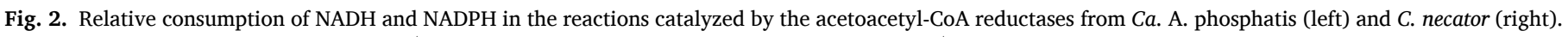
The input concentration ranges were $\mathrm{NAD}^{+}$: from 147 to $143 \mu \mathrm{M}$, NADH: from 3 to $7 \mu \mathrm{M}$, NADP ${ }^{+}$: from 50 to $6 \mu \mathrm{M}$ and NADPH: from 50 to $94 \mu \mathrm{M}$. 

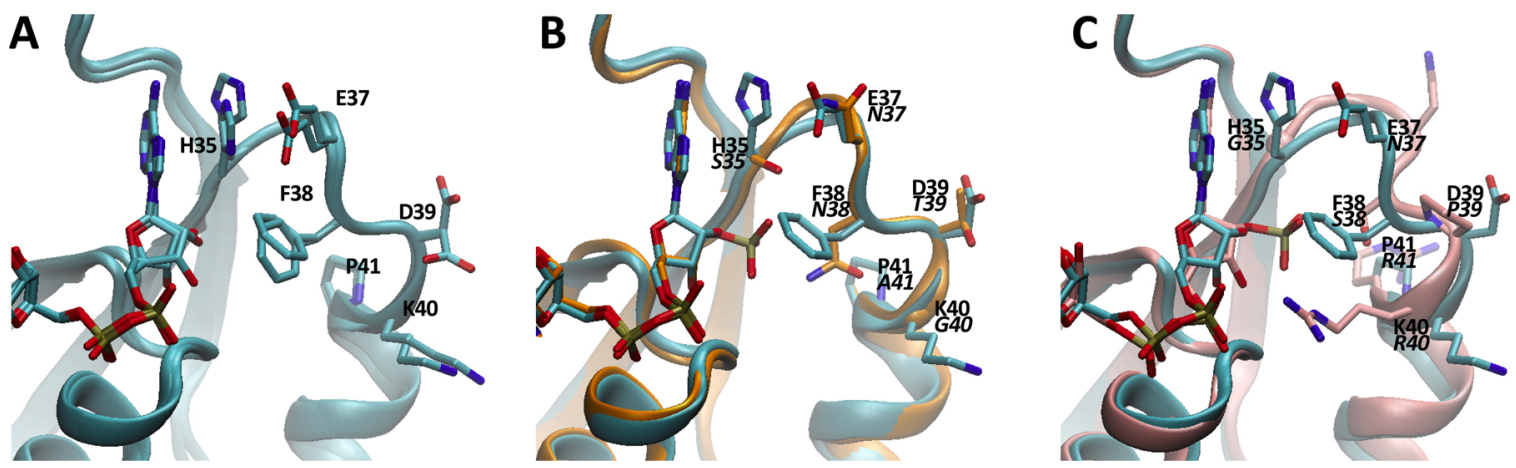

Fig. 3. Involvement of residues of the $\beta_{2} \alpha_{2}$ loop in the cofactor preference. In B and C, labels indicate homologous residues in the homology models (above) and the templates (below, italics). A: The superposition of subunits C and D of the homology model of the acetoacetyl-CoA reductase from Ca. A. phosphatis in complex with $\mathrm{NAD}^{+}$, shows low conformational variability between subunits. B: Superposition of subunit D with subunit D of the acetoacetyl-CoA reductase from B. cenocepacia (PDB 4K6F, colored in orange), in complex with $\mathrm{NADP}^{+}$. C: Superposition of subunit D of the acetoacetyl-CoA reductase from Ca. A. phosphatis with subunit A of the acetoacetyl-CoA reductase from C. necator (PDB 4N5N, colored in pink), in complex with NADP ${ }^{+}$. B and C illustrate the steric hindrance of the voluminous F38 with the 2'-phosphate of $\mathrm{NADP}^{+}$, as well as the impossibility of the positively charged K40 in the acetoacetyl-CoA reductase from Ca. A. phosphatis to establish a salt bridge with the 2'-phosphate of the $\mathrm{NADP}^{+}$, as $\mathrm{R} 40$ in the acetoacetyl-CoA reductase from $C$. necator does.

alignment of primary structures, one might expect that $\mathrm{AAR}^{\mathrm{CAp}}$ should also prefer NADPH. However, the presence of a proline residue at the following position (P41) disrupts the $\alpha$-helix 2 structure such that the positively charged side-chain of K40 is moved away from the binding pocket (Fig. 3). In addition, the bulky side-chain of the F38 residue present in $\mathrm{AAR}^{\mathrm{CAp}}$ could produce steric hindrance with the 2'-phosphate of NADPH. On the other hand, interactions with NADH are not impaired by these structural features. Therefore, the displacement of the positively charged side-chain of K40 in combination with the presence of the bulky side-chain of F38 should be key structural traits determining the preference for NADH observed in AAR ${ }^{\mathrm{CAp}}$. Notably, this combination of structural features is not shared with other acetoacetyl-CoA reductases that reportedly can use NADH as substrate (Supplementary Fig. 2).

To substantiate our hypothesis about the role of these residues in the observed cofactor specificity, we generated, by artificial synthesis, a gene encoding for a mutant enzyme. In this mutant enzyme, the original segment between the amino acids N37 and R41 of the NADPH-preferring $\mathrm{AAR}^{\mathrm{Cn}}$ was replaced by the corresponding amino acids from $\mathrm{AAR}^{\mathrm{CAp}}$ (E37 to P41). This mutant, named AAR ${ }^{\text {Chimera }}$, was cloned in the vector pCOLA-duet-1 and it was over-expressed in E. coli BL21(DE3) cells. For comparison, E. coli BL21(DE3) cells carrying the empty plasmid pCOLAduet-1, the plasmid pCOLA-phaB-Cnecator (enabling the overexpression of the parental $\mathrm{AAR}^{\mathrm{Cn}}$ ) and the plasmid pCOLA-His-phaBCAp6 were grown in parallel. Specific acetoacetyl-CoA reductase activities, using NADH and NADPH, were evaluated in cell-free extracts coming from these strains. The average NADH- and NADPH-linked activities recorded in the cell-free extract from the cells carrying the empty plasmid pCOLA-duet-1 were considered as background signals and subtracted to the activities obtained with the other extracts. The net NADH- and NADPH-linked activities recorded in the cell-free extracts strongly suggested that $\mathrm{AAR}^{\text {Chimera }}$ has a cofactor preference somewhere between the parental NADPH-preferring $\mathrm{AAR}^{\mathrm{Cn}}$ and the NADHpreferring $\mathrm{AAR}^{\mathrm{CAp}}$ (Table 3).

$\mathrm{AAR}^{\text {Chimera }}$ was purified, and reactions using NADH or NADPH as cofactor were kinetically characterized by progress curves analysis. The results obtained with purified enzyme are consistent with the data obtained with cell-free extracts (Table 3). For comparison, some kinetic parameters of the parental NADPH-preferring $\mathrm{AAR}^{\mathrm{Cn}}$ and the NADHpreferring $A A R^{C A p}$ were included. In the case of $A A R^{C n}$, kinetic parameters obtained with purified enzyme were found in the reports of Haywood and co-workers (Haywood et al., 1988) and Matsumoto and co-workers (Matsumoto et al., 2013). While Matsumoto and co-workers characterized the enzyme activity using only NADPH, Haywood and co-workers studied the activities with NADH and NADPH. Then, we chose the data reported by the latter to compare the cofactor preferences among $\mathrm{AAR}^{\mathrm{Cn}}, \mathrm{AAR}^{\text {Chimera }}$ and $\mathrm{AAR}^{\mathrm{CAp}}$ using the parameter $\left(k_{\text {cat }} / K_{\mathrm{M}}\right.$ $\mathrm{NADH}) /\left(k_{\text {cat }} / K_{\mathrm{M}}{ }^{\mathrm{NADPH}}\right)$ (Table 3$)$. Despite the differences between the kinetic parameters reported by Haywood and co-workers and Matsumoto and co-workers, their estimates of $\left(k_{\text {cat }} / K_{\mathrm{M}}{ }^{\mathrm{NADPH}}\right)$ are similar $\left(2.62 \times 10^{5} \mathrm{M}^{-1} \mathrm{~s}^{-1}\right.$ and $6.85 \times 10^{5} \mathrm{M}^{-1} \mathrm{~s}^{-1}$, respectively). Therefore, either comparing the observations from Haywood and co-workers or Matsumoto and co-workers, our conclusion about the shift in cofactor specificity in $\mathrm{AAR}^{\text {Chimera }}$ respect to the parental $\mathrm{AAR}^{\mathrm{Cn}}$ would be qualitatively similar.

It was possible to observe that, in comparison with the parental $\mathrm{AAR}^{\mathrm{Cn}}$, the modifications improved the performance using NADH while impaired the performance using NADPH (Table 3). Although a full reversion of the cofactor specificity of $\mathrm{AAR}^{\mathrm{Cn}}$ will require further modifications, our results endorse the proposed hypothesis regarding the role of the residues between E37 and P41 as structural determinants of the NADH preference observed for AAR ${ }^{\mathrm{CAp}}$. Moreover, further understanding of the structural determinants in the dinucleotide binding

Table 3

Kinetic properties of acetoacetyl-CoA reductases with different cofactor preference.

\begin{tabular}{|c|c|c|c|c|c|c|c|c|}
\hline & \multicolumn{3}{|c|}{ Data obtained with cell-free extracts ${ }^{(a)}$} & \multicolumn{5}{|c|}{ Data obtained with purified enzymes } \\
\hline & $\begin{array}{l}\text { sp. activity NADH } \\
\text { (U/mg) }\end{array}$ & $\begin{array}{l}\text { sp. activity NADPH } \\
\text { (U/mg) }\end{array}$ & $\begin{array}{l}\text { Ratio sp. } \\
\text { activities }\end{array}$ & $k_{c a t}^{\mathrm{NADH}}\left(\mathrm{s}^{-1}\right)$ & $K_{M}^{\mathrm{NADH}}(\mu \mathrm{M})$ & $k_{c a t}^{\mathrm{NADH}}\left(\mathrm{s}^{-1}\right)$ & $K_{M}^{\mathrm{NADPH}}(\mu \mathrm{M})$ & $\begin{array}{l}\left(k_{\text {cat }} / \mathrm{K}_{\mathrm{M}}{ }^{\mathrm{NADH}}\right) / \\
\left(k_{\text {cat }} / \mathrm{K}_{\mathrm{M}}{ }^{\mathrm{NADPH}}\right)\end{array}$ \\
\hline $\mathrm{AAR}^{\mathrm{Cn}}$ & $0.13 \pm 0.07$ & $0.68 \pm 0.13$ & 0.19 & $1.0^{(\mathrm{b})}$ & $400^{(b)}$ & $5^{(b)}$ & $19^{\text {(b) }}$ & 0.01 \\
\hline $\mathrm{AAR}^{\text {Chimera }}$ & $0.93 \pm 0.18$ & $0.29 \pm 0.07$ & 3.18 & $5.14 \pm 0.03$ & $77 \pm 3$ & $9.30 \pm 0.05$ & $665 \pm 6$ & 4.75 \\
\hline $\mathrm{AAR}^{\mathrm{CAp}}$ & $1.96 \pm 0.11$ & $0.25 \pm 0.03$ & 7.88 & $8.92 \pm 0.05$ & $7.7 \pm 0.5$ & $0.095 \pm 0.002$ & $44.3 \pm 2$ & 569 \\
\hline
\end{tabular}

(a) Cell-free extracts from E. coli BL21DE3 cells over-expressing the acetoacetyl-CoA reductases from C. necator (AAR ${ }^{\mathrm{Cn}}$ ), Ca. A. phosphatis (AAR ${ }^{\mathrm{CAp}}$ ) and the artificial Chimera $\left(\mathrm{AAR}^{\mathrm{Chimera}}\right)$. For details about cell-free extracts preparation and rate estimates see section Methods. NAD(P)H concentration was $200 \mu \mathrm{M}$ and acetoacetylCoA concentration was $70 \mu \mathrm{M} .1 \mathrm{U} / \mathrm{mg}=1 \mu \mathrm{mol}^{*} \mathrm{~min}^{-1}$ per milligram of cytoplasmic proteins.

(b) Data from Haywood and co-workers. The $k_{\text {cat }}$ were calculated from the reported $V^{\max }(2.6 \mathrm{U} / \mathrm{mg}$ for NADH, $13 \mathrm{U} / \mathrm{mg}$ for NADPH) and the molecular weight of the monomer (23 KDa). 
pocket (Supplementary Material 2, Supplementary Fig. 3) could be useful for genomic screenings looking for other putative NADHpreferring acetoacetyl-CoA reductases or could be valuable as starting point for further protein/metabolic engineering efforts.

\section{4. $A A R^{C A p}$ can be engaged in $P H B$ accumulation}

To verify in vivo functionality of $\mathrm{AAR}^{\mathrm{CAp}}$, an operon was assembled joining the phaCA genes from $C$. necator with the phaB ${ }^{\mathrm{CAp}} 6$ gene; and this operon was placed under the control of T7 promoter. The resultant plasmid was introduced in E. coli MG1655(DE3) cells, which are able to express T7 RNA polymerase upon induction with IPTG (Supplementary Material 3). NADH-linked acetoacetyl-CoA reductase activity was observed, and this activity increased while increasing IPTG concentration in the medium (Supplementary Figure 4). Therefore, it was concluded that it was possible to regulate the expression of the genes phaCA ${ }^{\text {Cnecator }}$ phaB ${ }^{\mathrm{CAp}}$ placed under the control of $\mathrm{T} 7$ promoter. Moreover, using the estimated kinetic parameters and the observed specific activity, it was possible to calculate the abundancy of $\mathrm{AAR}^{\mathrm{CAp}}$ and the metabolic flux that such enzyme capacity can sustain (Supplementary Material 3). According to such calculations, with the maximum observed specific activity $(11 \mathrm{nmol} / \mathrm{min} / \mathrm{mg}$ ), it should be possible to sustain a maximum flux around $0.08 \mathrm{mmol} / \mathrm{gCDW} / \mathrm{h}$ (Supplementary Figure 5).

However, the observation of NADH-linked acetoacetyl-CoA reductase activity does not necessarily guarantee the expression of other genes placed in the same operon nor an in vivo operative PHB pathway. Therefore, we next sought to link the accumulation of PHB in E. coli to the presence of the operon $p h a C A^{\text {Cnecator }}$ phaB $^{\mathrm{CAp}}$ in order to provide evidence of (i) in vivo functionality of the operon phaCA ${ }^{\text {Cnecator }}$ phaB ${ }^{\mathrm{CAp}}$ and (ii) the ability of $\mathrm{AAR}^{\mathrm{CAp}}$ to be engaged in an PHB accumulation process.

Aiming a more accurate tracking of the carbon and electrons in the system, we chose to study the PHB accumulation using a continuous culture. Given the clear preference for $\mathrm{NADH}$ of $\mathrm{AAR}^{\mathrm{CAp}}$, we reasoned that a reduction in oxygen supply must lead to an increase in PHB accumulation, provided the generation of other fermentation products be reduced. To ensure a reduced/null generation of other fermentation products, $E$. coli MG1655(DE3) ${ }^{\Delta 5}(\mathrm{~F}-\lambda-i l v G-r f b-50 r p h-1$ (DE3) $\Delta a d h E$ $\Delta a d h P \Delta l d h A \Delta p t a \Delta m h p F)$ was chosen as a suitable strain to express the operon phaCA ${ }^{\text {Cnecator }}$ phaB ${ }^{\mathrm{CAp}}$.

Given the relatively low acetoacetyl-CoA reductase activity observed in the cell-free extracts from $E$. coli cells expressing the operon pha$C A^{\text {Cnecator }}$ phaB ${ }^{\mathrm{CAp}}$ (Supplementary Figure 4) in comparison with the acetoacetyl-CoA reductase activity registered in the cell-free extract from the Ca. A. phosphatis-enriched mixed culture (Table 1), we decided to not integrate this operon in the chromosome. Nevertheless, to avoid the use of antibiotic during a continuous culture, the genes $\csc A B K$ from E. coli $\mathrm{W}$ were introduced in the same plasmid already carrying the operon phaCA ${ }^{\text {Cnecator }}$ phaB ${ }^{\mathrm{CAp}}$, resulting the plasmid pCOLA-phaCA ${ }^{\text {Cne- }}$ ${ }^{\text {cator }}{ }_{\text {phaB }}{ }^{\mathrm{CAp}}$-cscABK. This way, the use of sucrose as the sole carbon source was the selection pressure to maintain the plasmid, as previously demonstrated (Olavarria et al., 2019).

The continuous growth of $E$. coli MG1655(DE3) ${ }^{\Delta 5}$ transformed with the plasmid pCOLA-phaCA ${ }^{\text {Cnecator }}$ phaB $^{\text {CAp }}$-cscABK, using sucrose as the sole carbon source, was studied under oxygen limiting conditions, at a dilution rate of $0.1 \mathrm{~h}^{-1}$. To enable the expression of the operon pha$C A^{\text {Cnecator }}$ phaB ${ }^{\mathrm{CAp}}$, the feeding solution was supplemented with IPTG $(100 \mu \mathrm{M})$.

Being aware of previous reports of genetic instabilities when using episomal expression systems enabling the sucrose consumption (Bruschi et al., 2012), the presence of the plasmid pCOLA-phaCA ${ }^{\text {Cnecator- }}$ phaB ${ }^{\mathrm{CAp}}$-cscABK was monitored by colony-PCR. In our conditions, no plasmid loss was verified (data not shown).

Two steady-states, characterized by different levels of oxygen limitation, were characterized (Table 4). Aiming to achieve a stable oxygen consumption rate below $2.9 \mathrm{mmol} \mathrm{O}_{2} / \mathrm{gCDW} / \mathrm{h}$, we tried to further
Table 4

Reconciled rates and other relevant parameters obtained during the study of the two steady-states characterized by different levels of oxygen limitation.

\begin{tabular}{lll}
\hline & Steady-state 1 & Steady-state 2 \\
\hline $\mathrm{q}_{\mathrm{x}}\left(\mathrm{h}^{-1}\right)$ & $0.1098 \pm 0.0041$ & $0.0939 \pm 0.0041$ \\
$\mathrm{q}_{\mathrm{O} 2}(\mathrm{mmol} / \mathrm{gCDW} / \mathrm{h})$ & $-4.1004 \pm 0.0174$ & $-2.8381 \pm 0.0105$ \\
$\mathrm{q}_{\mathrm{CO} 2}(\mathrm{mmol} / \mathrm{gCDW} / \mathrm{h})$ & $4.4285 \pm 0.0183$ & $3.1196 \pm 0.0158$ \\
$\mathrm{q}_{\text {sucrose }}(\mathrm{mmol} / \mathrm{gCDW} / \mathrm{h})$ & $-0.7906 \pm 0.0155$ & $-0.6675 \pm 0.0163$ \\
$\mathrm{q}_{\text {acetate }}(\mathrm{mmol} / \mathrm{gCDW} / \mathrm{h})$ & $0.0062 \pm 0.002$ & $0.198 \pm 0.0239$ \\
$\mathrm{q}_{\text {lactate }}(\mathrm{mmol} / \mathrm{gCDW} / \mathrm{h})$ & $0.0495 \pm 0.006$ & $0.0043 \pm 0.0004$ \\
$\mathrm{q}_{\text {succinate }}(\mathrm{mmol} / \mathrm{gCDW} / \mathrm{h})$ & $0.0377 \pm 0.005$ & $0.0222 \pm 0.004$ \\
$\mathrm{q}_{\text {formate }}(\mathrm{mmol} / \mathrm{gCDW} / \mathrm{h})$ & $\mathrm{b} . \mathrm{d.1}$ & $0.0736 \pm 0.0079$ \\
$\mathrm{q}_{\mathrm{PHB}}(\mathrm{mmol} / \mathrm{gCDW} / \mathrm{h})$ & $0.0023 \pm 0.0001$ & $0.0676 \pm 0.0034$ \\
Biomass yield $(\mathrm{CmolX} / \mathrm{CmolS})$ & $0.5 \pm 0.022$ & $0.505 \pm 0.026$ \\
Biomass yield $(\mathrm{gCDW} / \mathrm{gS})$ & 0.406 & 0.410 \\
electrons from sucrose going to oxygen & 43 & 35 \\
$\quad$ (\%) & & 3.8 \\
electrons from sucrose going to PHB $(\%)$ & 0.1 & 25.5 \\
Y & 0.7 & 5.8 \\
PHB $(\mathrm{mgPHB} / \mathrm{gS})$ & 0.2 & 0.31 \\
PHB titer $(\mathrm{g} / \mathrm{L})$ & 0.01 & \\
\hline
\end{tabular}

b.d.l.: below detection level.

For the interconversion between CmolX and gCDW, biomass was considered as a "molecule" with a molecular weight $\mathrm{Mwx}=23.184 \mathrm{gCDW} / \mathrm{CmolX}$.

decrease the oxygen supply while keeping the same dilution rate. However, this attempt brought instabilities in off-gas composition that were not stabilized after ten residence times.

Given the inability of wild-type $E$. coli to produce PHB, the observed accumulation, irrespective to the obtained PHB titers, confirmed the ability of $\mathrm{AAR}^{\mathrm{CAp}}$ to be engaged in $\mathrm{PHB}$ accumulation and confirmed the in vivo functionality of the operon phaCA ${ }^{\text {Cnecator }} p h a B^{\mathrm{CAp}}$. Moreover, in the steady-state with the lowest oxygen consumption rate, PHB accumulation increased more than 30 times respect to the other steady-state (Table 4).

From a historical perspective, there are previous reports of increments in PHB accumulation linked to oxygen limitation in Azotobacter beijerinckii (Senior et al., 1972) and Azotobacter vinelandii (Page and Knosp, 1989). One potential explanation for those observations was the use of NADH to drive PHB accumulation. However, kinetic characterizations of the acetoacetyl-CoA reductases present in those bacteria showed that they prefer NADPH instead of NADH (Ritchie et al., 1971; Manchak and Page, 1994). In our case, the kinetic characterization clearly indicated that, in the physiological conditions, $\mathrm{AAR}^{\mathrm{CAp}}$ prefers NADH. Different to previous reports claiming NADH-driven accumulation of PHB using the acetoacetyl-CoA reductases from A. vinosum and $H$. bluephagenesis, we are endorsing our claiming with a kinetic analysis considering physiologically relevant and dynamic concentrations of $\mathrm{NAD}^{+}, \mathrm{NADP}^{+}, \mathrm{NADH}$ and NADPH.

Finally, according to several previous observations, Ca. A. phosphatis accumulates PHB in anaerobic conditions coupled to glycogen mobilization and acetate uptake. Different to A. vinosum or H. bluephagenesis, $\mathrm{Ca}$. A. phosphatis does not have an NADPH-producing oxidative branch of the pentose-phosphate pathway. This way, the oxidation of glucose or glucose equivalents yields electrons carried only by NADH. Because PHB has a higher electron/carbon ratio than glucose, polymer accumulation could operate as a mechanism to re-oxidize $\mathrm{NADH}$ in such conditions. One way to enable this re-oxidation is having an NADH-preferring acetoacetyl-CoA reductase. Therefore, the NADH-preference of AAR ${ }^{\mathrm{CAp}}$ is consistent with the ecological and biochemical conditions present during PHB accumulation in Ca. A. phosphatis, highlighting the importance of a multi-disciplinary approach when looking for enzymes with different/new properties.

\section{Conclusions}

In this research, we identified and characterized an acetoacetyl-CoA reductase that prefers NADH over NADPH in a wide range of 
physiologically feasible $\mathrm{NAD}(\mathrm{P})(\mathrm{H})$ concentations. Moreover, a structural analysis and further kinetic characterization of a mutant enzyme indicated a group of key amino acids with a relevant role in the observed cofactor specificity, opening the way to further protein engineering approaches and to the quest for other NADH-specific acetoacetyl-CoA reductases in other (meta)genomes. Finally, evidence of engagement of this NADH-preferring acetoacetyl-CoA reductase in PHB accumulation was shown.

The identification of an NADH-preferring acetoacetyl-CoA reductase able to participate in PHB accumulation is a key piece to develop metabolic engineering strategies envisioning generation of PHB as a fermentation product. Yet, this piece alone does not solve the mismatch between catabolic supply and PHB formation demand of acetyl-CoA and electrons (Fig. 1). Therefore, the substitution of the two sources of acetyl-CoA (external acetate and internal glycogen) present in Ca. A. phosphatis by a single external source, together with the removal of eventual energetic and kinetic bottlenecks, should be the focus of future metabolic engineering strategies envisioning anaerobic generation of PHB as a single/main fermentation product.

\section{Funding}

This work was supported by the joint research program NWO-FAPESP of The Netherlands Organization for Scientific Research (NWO) and São Paulo Research Foundation (FAPESP) (NWO: BRAZIL.2013.018 - FAPESP: 2013/50357-2). The contributions of Karel Olavarria and M.C.M. van Loosdrecht were also supported by a SIAM Gravitation Grant (024.002.002) from the Netherlands Ministry of Education, Culture and Science (OCW) and NWO. The authors declare they do not have any potential conflict of interest.

\section{CRediT authorship contribution statement}

Karel Olavarria: Conceptualization, Methodology, Software, Validation, Formal analysis, Investigation, Data curation, Writing - original draft, Writing - review \& editing, Visualization, Supervision, Funding acquisition. Alexandre Carnet: Validation, Formal analysis, Investigation, Data curation, Writing - review \& editing. Joachim van Renselaar: Methodology, Formal analysis, Investigation. Caspar Quakkelaar: Formal analysis, Investigation, Data curation. Ricardo Cabrera: Methodology, Resources, Writing - review \& editing. Leonor Guedes da Silva: Validation, Investigation. Aron L. Smids: Formal analysis, Investigation, Data curation. Pablo Andres Villalobos: Methodology, Software. Mark C.M. van Loosdrecht: Conceptualization, Resources, Funding acquisition. S. Aljoscha Wahl: Conceptualization, Methodology, Software, Resources, Writing - review \& editing, Supervision, Project administration, Funding acquisition.

\section{Declaration of Competing Interest}

The authors report no declarations of interest.

\section{Appendix A. Supplementary data}

Supplementary material related to this article can be found, in the online version, at doi:https://doi.org/10.1016/j.jbiotec.2020.10.022.

\section{References}

Lemoigne, M., 1926. Produits de dehydration et de polymerisation de l'acide Boxobutyrique. Bulletin de la Société de Chimie Biologique 8, 770-782.

Cueto-Rojas, H.F., van Maris, A.J.A., Wahl, S.A., Heijnen, J.J., 2015. Thermodynamicsbased design of microbial cell factories for anaerobic product formation. Trends in Biotechnology 33, 534-546.

Carlson, R., Wlaschin, A., Srienc, F., 2005. Kinetic studies and biochemical pathway analysis of anaerobic poly-(R)-3-hydroxybutyric acid synthesis in Escherichia coli. Appl Environ Microbiol 71, 713-720.
Schubert, P., Steinbuchel, A., Schlegel, H.G., 1988. Cloning of the Alcaligenes eutrophus genes for synthesis of poly-beta-hydroxybutyric acid (PHB) and synthesis of PHB in Escherichia coli. J Bacteriol 170, 5837-5847.

Chen, Z., Zhao, L., Ji, Y., Wen, Q., Huang, L., 2019. Reconsideration on the effect of nitrogen on mixed culture polyhydroxyalkanoate production toward high organic loading enrichment history. Frontiers of Environmental Science \& Engineering 13 , 54.

de Las Heras, A.M., Portugal-Nunes, D.J., Rizza, N., Sandstrom, A.G., GorwaGrauslund, M.F, 2016. Anaerobic poly-3-D-hydroxybutyrate production from xylose in recombinant Saccharomyces cerevisiae using a NADH-dependent acetoacetyl-CoA reductase. Microb Cell Fact 15, 197.

Ling, C., Qiao, G.Q., Shuai, B.W., Olavarria, K., Yin, J., Xiang, R.J., Song, K.N., Shen, Y. H., Guo, Y., Chen, G.Q., 2018. Engineering NADH/NAD(+) ratio in Halomonas bluephagenesis for enhanced production of polyhydroxyalkanoates (PHA). Metab Eng 49, 275-286.

Andersen, K.B., von Meyenburg, K., 1977. Charges of nicotinamide adenine nucleotides and adenylate energy charge as regulatory parameters of the metabolism in Escherichia coli. J Biol Chem 252, 4151-4156.

de Graef, M.R., Alexeeva, S., Snoep, J.L., Teixeira de Mattos, M.J., 1999. The steady-state internal redox state (NADH/NAD) reflects the external redox state and is correlated with catabolic adaptation in Escherichia coli. J Bacteriol 181, 2351-2357.

Krapp, A.R., Victoria Humbert, M., Carrillo, N., 2011. The soxRS response of Escherichia coli can be induced in the absence of oxidative stress and oxygen by modulation of NADPH content. Microbiology-Sgm 157, 957-965.

Garcia Martin, H., Ivanova, N., Kunin, V., Warnecke, F., Barry, K.W., McHardy, A.C., Yeates, C., He, S., Salamov, A.A., Szeto, E., Dalin, E., Putnam, N.H., Shapiro, H.J., Pangilinan, J.L., Rigoutsos, I., Kyrpides, N.C., Blackall, L.L., McMahon, K.D., Hugenholtz, P., 2006. Metagenomic analysis of two enhanced biological phosphorus removal (EBPR) sludge communities. Nat Biotechnol 24, 1263-1269.

Reich, J.G., Sel'kov, E.E., 1981. Energy metabolism of the cell : a theoretical treatise. Academic Press, London; New York.

Spaans, S.K., Weusthuis, R.A., van der Oost, J., Kengen, S.W., 2015. NADPH-generating systems in bacteria and archaea. Front Microbiol 6, 742.

Oyserman, B.O., Noguera, D.R., del Rio, T.G., Tringe, S.G., McMahon, K.D., 2016. Metatranscriptomic insights on gene expression and regulatory controls in Candidatus Accumulibacter phosphatis. The ISME journal 10, 810-822.

Smolders, G.J., van der Meij, J., van Loosdrecht, M.C., Heijnen, J.J., 1994. Model of the anaerobic metabolism of the biological phosphorus removal process: Stoichiometry and $\mathrm{pH}$ influence. Biotechnol Bioeng 43, 461-470.

Bradford, M.M., 1976. A rapid and sensitive method for the quantitation of microgram quantities of protein utilizing the principle of protein-dye binding. Anal Biochem 72, 248-254.

Olavarria, K., Marone, M.P., da Costa Oliveira, H., Roncallo, J.C., da Costa Vasconcelos, F.N., da Silva, L.F, Gomez, J.G., 2015. Quantifying NAD(P)H production in the upper Entner-Doudoroff pathway from Pseudomonas putida KT2440. FEBS Open Bio 5, 908-915.

Cavalieri, R.L., Sable, H.Z., 1974. Pitfalls in the study of steady state kinetics of enzymes: spurious inhibition patterns due to stray light errors. Anal Biochem 59, 122-128.

Stern, J.R., 1956. Optical properties of aceto-acetyl-S-coenzyme A and its metal chelates. J Biol Chem 221, 33-44.

Selwyn, M.J., 1965. A simple test for inactivation of an enzyme during assay. Biochim Biophys Acta 105, 193-195.

Kuzmic, P., 1996. Program DYNAFIT for the analysis of enzyme kinetic data: Application to HIV proteinase. Analytical Biochemistry 237, 260-273.

Sali, A., Blundell, T.L., 1993. Comparative protein modelling by satisfaction of spatial restraints. J Mol Biol 234, 779-815.

Krieger, E., Joo, K., Lee, J., Lee, J., Raman, S., Thompson, J., Tyka, M., Baker, D., Karplus, K., 2009. Improving physical realism, stereochemistry, and side-chain accuracy in homology modeling: Four approaches that performed well in CASP8. Proteins 77 (Suppl 9), 114-122.

Humphrey, W., Dalke, A., Schulten, K., 1996. VMD: Visual molecular dynamics. Journal of Molecular Graphics \& Modelling 14, 33-38.

Roberts, E., Eargle, J., Wright, D., Luthey-Schulten, Z., 2006. MultiSeq: unifying sequence and structure data for evolutionary analysis. BMC Bioinformatics 7, 382.

Olavarria, K., Fina, A., Velasco, M.I., van Loosdrecht, M.C.M., Wahl, S.A., 2019. Metabolism of sucrose in a non-fermentative Escherichia coli under oxygen limitation. Applied Microbiology and Biotechnology.

Velasco Alvarez, M.I., Ten Pierick, A., van Dam, P.T.N., Maleki Seifar, R., van Loosdrecht, M.C.M., Wahl, S.A., 2017. Microscale Quantitative Analysis of Polyhydroxybutyrate in Prokaryotes Using IDMS. Metabolites 7.

Haywood, G.W., Anderson, A.J., Chu, L., Dawes, E.A., 1988. The role of NADH- and NADPH-linked acetoacetyl-CoA reductases in the poly-3-hydroxybutyrate synthesizing organism Alcaligenes eutrophus FEMS Microbiology Letters Volume 52, Issue 3. FEMS Microbiology Letters.

Kim, J., Chang, J.H., Kim, E.J., Kim, K.J., 2014. Crystal structure of (R)-3hydroxybutyryl-CoA dehydrogenase PhaB from Ralstonia eutropha. Biochem Biophys Res Commun 443, 783-788.

Fukui, T., Ito, M., Saito, T., Tomita, K., 1987. Purification and characterization of NADPlinked acetoacetyl-CoA reductase from Zoogloea ramigera I-16-M. Biochim Biophys Acta 917, 365-371.

Ploux, O., Masamune, S., Walsh, C.T., 1988. The NADPH-linked acetoacetyl-CoA reductase from Zoogloea ramigera. Characterization and mechanistic studies of the cloned enzyme over-produced in Escherichia coli. Eur J Biochem 174, 177-182.

Mothes, G., Babel, W., 1994. Methylobacterium rhodesianum MB 126 possesses two acetoacetyl-CoA reductases. Archives of Microbiology 161, 277-280. 
Rohwer, J.M., Hanekom, A.J., Crous, C., Snoep, J.L., Hofmeyr, J.H., 2006. Evaluation of a simplified generic bi-substrate rate equation for computational systems biology. Syst Biol (Stevenage) 153, 338-341.

Ritchie, G.A., Senior, P.J., Dawes, E.A., 1971. The purification and characterization of acetoacetyl-coenzyme A reductase from Azotobacter beijerinckii. Biochem J 121, 309-316.

Flamholz, A., Noor, E., Bar-Even, A., Milo, R., 2012. eQuilibrator-the biochemical thermodynamics calculator. Nucleic Acids Res 40, D770-775.

Canelas, A.B., van Gulik, W.M., Heijnen, J.J., 2008. Determination of the cytosolic free NAD/NADH ratio in Saccharomyces cerevisiae under steady-state and highly dynamic conditions. Biotechnology and Bioengineering 100, 734-743.

Kummel, A., Panke, S., Heinemann, M., 2006. Putative regulatory sites unraveled by network-embedded thermodynamic analysis of metabolome data. Mol Syst Biol 2 (2006), 0034.

Henry, C.S., Broadbelt, L.J., Hatzimanikatis, V., 2007. Thermodynamics-based metabolic flux analysis. Biophys J 92, 1792-1805.

Chassagnole, C., Noisommit-Rizzi, N., Schmid, J.W., Mauch, K., Reuss, M., 2002 Dynamic modeling of the central carbon metabolism of Escherichia coli. Biotechnology and Bioengineering 79, 53-73.

Bennett, B.D., Kimball, E.H., Gao, M., Osterhout, R., Van Dien, S.J., Rabinowitz, J.D., 2009. Absolute metabolite concentrations and implied enzyme active site occupancy in Escherichia coli. Nat Chem Biol 5, 593-599.

Lan, E.I., Liao, J.C., 2012. ATP drives direct photosynthetic production of 1-butanol in cyanobacteria. Proc Natl Acad Sci U S A 109, 6018-6023.
Tippmann, S., Anfelt, J., David, F., Rand, J.M., Siewers, V., Uhlén, M., Nielsen, J., Hudson, E.P., 2017. Affibody Scaffolds Improve Sesquiterpene Production in Saccharomyces cerevisiae. ACS Synth Biol 6, 19-28.

Vögeli, B., Engilberge, S., Girard, E., Riobé, F., Maury, O., Erb, T.J., Shima, S., Wagner, T., 2018. Archaeal acetoacetyl-CoA thiolase/HMG-CoA synthase complex channels the intermediate via a fused CoA-binding site. Proc Natl Acad Sci U S A $115,3380-3385$

Matsumoto, K. i., Tanaka, Y., Watanabe, T., Motohashi, R., Ikeda, K., Tobitani, K., Yao, M., Tanaka, I., Taguchi, S., 2013. Directed Evolution and Structural Analysis of NADPH-Dependent Acetoacetyl Coenzyme A (Acetoacetyl-CoA) Reductase from Ralstonia eutropha Reveals Two Mutations Responsible for Enhanced Kinetics. Applied and environmental microbiology 79, 6134-6139.

Bruschi, M., Boyes, S.J., Sugiarto, H., Nielsen, L.K., Vickers, C.E., 2012. A transferable sucrose utilization approach for non-sucrose-utilizing Escherichia coli strains. Biotechnol Adv 30, 1001-1010.

Senior, P.J., Beech, G.A., Ritchie, G.A., Dawes, E.A., 1972. The role of oxygen limitation in the formation of poly- -hydroxybutyrate during batch and continuous culture of Azotobacter beijerinckii. Biochem J 128, 1193-1201.

Page, W.J., Knosp, O., 1989. Hyperproduction of Poly-beta-Hydroxybutyrate during Exponential Growth of Azotobacter vinelandii UWD. Appl Environ Microbiol 55, 1334-1339.

Manchak, J., Page, W.J., 1994. Control of polyhydroxyalkanoate synthesis in Azotobacter vinelandii strain UWD. Microbiology 140, 953-963. 